\title{
Fast Quantitative Analysis of Boric Acid by Gas Chromatography-Mass Spectrometry Coupled with a Simple and Selective Derivatization Reaction Using Triethanolamine
}

\author{
Li-Min Zeng, Hao-Yang Wang, and Yin-Long Guo \\ Shanghai Mass Spectrometry Center, Shanghai Institute of Organic Chemistry, Chinese Academy of Sciences, \\ Shanghai, China
}

\begin{abstract}
A fast, selective, and sensitive GC-MS method has been developed and validated for the determination of boric acid in the drinking water by derivatization with triethanolamine. This analytic strategy successfully converts the inorganic, nonvolatile boric acid $\mathrm{B}(\mathrm{OH})_{3}$ present in the drinking water to a volatile triethanolamine borate $\mathrm{B}\left(\mathrm{OCH}_{2} \mathrm{CH}_{2}\right)_{3} \mathrm{~N}$ in a quantitive manner, which facilitates the GC measurement. The SIM mode was applied in the analysis and showed high accuracy, specificity, and reproducibility, as well as reducing the matrix effect effectively. The calibration curve was obtained from $0.01 \mu \mathrm{g} / \mathrm{mL}$ to $10.0 \mu \mathrm{g} / \mathrm{mL}$ with a satisfactory correlation coefficient of 0.9988 . The limit of detection for boric acid was $0.04 \mu \mathrm{g} / \mathrm{L}$. Then the method was applied for detection of the amount of boric acid in bottled drinking water and the results are in accordance with the reported concentration value of boric acid. This study offers a perspective into the utility of GC-MS as an alternate quantitative tool for detection of $\mathrm{B}(\mathrm{OH})_{3}$, even for detection of boron in various other samples by digesting the boron compounds to boric acid. (J Am Soc Mass Spectrom 2010, 21, 482-485) (c) 2010 American Society for Mass Spectrometry
\end{abstract}

B oron is considered to be an essential trace element for human beings and animals [1]. It can keep bones and joints functioning normally and helps to prevent osteoporosis and osteoarthritis. However, the cumulative boron in animals, plants, and water constitutes a potential hazard to the human beings [2]. The excessive intake of boron was reported to bring about some bad influences such as reproductive and developmental toxicity in animal experiments. The guideline value of $B 0.5 \mathrm{mg} / \mathrm{L}$ in drinking water is designated as provisional by the World Health Organization (WHO) and the acceptable daily intake of boron was determined to be $18 \mathrm{mg} / \mathrm{d}$ [3].

Recently, boron has come to the forefront as a possible drinking water contaminant and the need of monitoring of boron content in water has been pointed out. There have been numerous researches on accurate, quick, and economic determination of boron in the form of boric acid. Previously, many spectrophotometric and fluorimetric methods were developed to measure boron concentrations. The colorimetric reagents included curmine, carmine, azomethine $\mathrm{H}$, and so on [4-9]. However, these methods suffered from poor sensitivity,

Address reprint requests to Professor Y. L. Guo, Shanghai Mass Spectrometry Center, Shanghai Institute of Organic Chemistry, Chinese Academy of Sciences, 345 Lingling Road, Shanghai 200032, China. E-mail: ylguo@ mail.sioc.ac.cn interference effect, and complicated procedure [4]. In the recent years, the most common methods for the determination of boric acid are inductively coupled plasma atomic emission spectrometry (ICP-AES) and inductively coupled plasma mass spectrometry (ICPMS) analysis because of their high sensitivity [10-13]. However, the ICP-AES analysis is often interfered by some element whose wavelength is near that of B. e.g., there is overlap of Fe at $249.782 \mathrm{~nm}$ on B at $249.773 \mathrm{~nm}$, and $\mathrm{Fe}$ at $249.653 \mathrm{~nm}$ on B at $249.678 \mathrm{~nm}$ [14]. Boron determination by ICP-AES is also affected by other species; for example, the presence of $\mathrm{Fe}$ and $\mathrm{Ni}$ depressed, while Mn and Ti enhanced, B signals [11]. The memory effect is also inevitable in the ICP analysis [15]. Moreover, the expensive apparatus needed in ICP analysis does not permit its use in most laboratories. To our best knowledge, no method is available for the determination of boric acid by gas chromatography-mass spectrometry.

Herein, we developed a gas chromatographic-mass spectrometric strategy for determination of boric acid in drinking water after converting the nonvolatile boric acid into its volatile form of triethanolamine borate by using triethanolamine as a derivative reagent. The experimental results showed that boric acid could form triethanolamine borate in quantitative yield, when reacted with excess triethanolamine, due to the special 
(a)

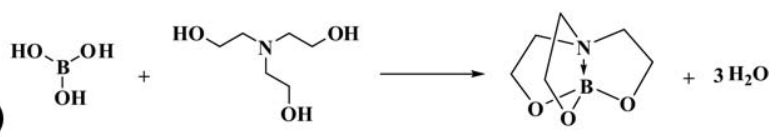

(b)

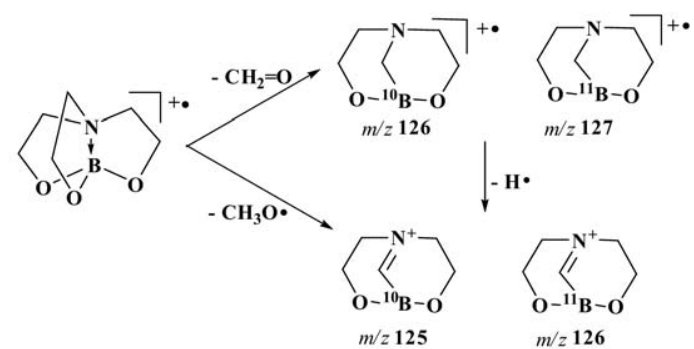

Scheme 1. The derivatization reaction of boric acid with triethanolamine (a) and the proposed formation of the fragment ions at $\mathrm{m} / \mathrm{z} 125,126$ and 127 (b).

stability of the "triptych" structure of triethanolamine borate (Scheme 1a) [16]. The nitrogen-boron bond in the structure of triethanolamine borate contributes much to its molecular stability [17]. Such a methodology facilitates the GC-MS detection of borate acid, and when applying selective ion monitoring (SIM) mode during MS measuring, it makes the whole method more reliable, sensitive, and reproducible due to reducing the matrix effect effectively in the analysis. By using this analysis method, we successfully detected the boric acid in drinking water and the result is comparable with the data reported in previous references. The detection of boron in other boron compounds could also be performed by transferring the boron compounds to boric acid by suitable sample preparation methods such as mixture-strong acid digestion or carbonization-aciddissolution method $[11,18,19]$. Thus, our method might be also used for analysis of other boron compounds with suitable sample preparation methods to convert these boron compounds to boric acid, as well as with methods to control the matrix effect in analysis.

\section{Experimental}

Boric acid $(99.99 \%)$ was purchased from Alfa Aesar (Ward Hill, MA, USA). Triethanolamine borate (97\%) was purchased from Sigma-Aldrich (St. Louis, MO, USA). Analytical grade triethanolamine and ethanol were obtained from SCRC (Sinopharm Chemical Reagent Co., China). HPLC-grade acetonitrile was purchased from Merck (KGaA, Darmstadt, Germany). All chemicals were used without further purification.

GC-MS analyses were carried out on a 7890 gas chromatograph interfaced to a 5973 mass detector (Agilent Technologies, Palo Alto, CA, USA), and a CTC Combi PAL automatic injector (Zwingen, Switzerland). Chromatographic separation was obtained on a DB5MS column $(30 \mathrm{~m} \times 0.25 \mathrm{~mm}$ i.d., $0.25 \mu \mathrm{m}$ film thickness; J and W Scientific, Folsom, CA, USA) using helium $(99.999 \%)$ as the carrier gas (flow rate, $1 \mathrm{~mL} /$ min). The GC injection port was maintained at $300{ }^{\circ} \mathrm{C}$ in split mode with a ratio of 100:1. The transfer line temperature was set at $280^{\circ} \mathrm{C}$ and the oven temperature was held at $250^{\circ} \mathrm{C}$ constantly for $8 \mathrm{~min}$.

The mass detector was operated in positive EI mode with the electron energy of $70 \mathrm{eV}$. The quadrupole and ion source temperature were $150{ }^{\circ} \mathrm{C}$ and $260^{\circ} \mathrm{C}$, respectively. Data handling and system operations were controlled by the MSD ChemStation software (rev. E. 01. 01). Qualitative analyses were operated in the full scan (TIC) mode, with a scan range from 30 to $400 \mathrm{amu}$. Quantitative analyses were performed in the selective ion monitoring (SIM) mode, with a dwell time of $100 \mathrm{~ms}$ for the characteristic ions of $m / z 125,126$, and 127.

A stock solution of boric acid was prepared in ethanol to yield a concentration of $1.0 \mathrm{mg} / \mathrm{mL}$. Standard solutions were prepared at concentrations: 0.010 $\mu \mathrm{g} / \mathrm{mL}, 0.050 \mu \mathrm{g} / \mathrm{mL}, 0.50 \mu \mathrm{g} / \mathrm{mL}, 1.0 \mu \mathrm{g} / \mathrm{mL}, 3.0$ $\mu \mathrm{g} / \mathrm{mL}, 7.0 \mu \mathrm{g} / \mathrm{mL}, 10.0 \mu \mathrm{g} / \mathrm{mL}$. Drinking water $(20.0$ $\mathrm{mL}$ ) was evaporated to dryness at about $55{ }^{\circ} \mathrm{C}$ under a stream of nitrogen. Then the residue was ready for derivatization. Derivatization was performed with 2.4 $\mathrm{mg}$ triethanolamine in $0.5 \mathrm{~mL}$ acetonitrile at $50^{\circ} \mathrm{C}$ for $1 \mathrm{~h}$. After derivatization, the mixture was reconstituted to $2.0 \mathrm{~mL}$ in acetonitrile. An aliquot of $1.0 \mu \mathrm{L}$ of the derivatized mixture was then injected into GC-MS instrument.

\section{Results and Discussion}

\section{Derivatization GC-MSAnalysis Conditions}

GC-MS analysis showed that the retention time of triethanolamine borate was $1.81 \mathrm{~min}$ in TIC mode (Supplemental Figure S1, which can be found in the electronic version of this article). The high abundant characteristic fragment ions of $m / z 125,126,127$ (fragmentation pathways were discussed in the supporting information) from triethanolamine borate in EI condition were chosen as the monitoring ions for the SIM mode. Our results showed that SIM mode detection effectively improves the sensitivity and reduces the matrix effect than TIC mode (Supplemental Figure S2). Thus, the SIM mode was used for the entire quantitative analysis.

Table 1. Recovery of boric acid in the analysis

\begin{tabular}{ccc}
\hline $\begin{array}{c}\text { Concentrations } \\
(\mu \mathrm{g} / \mathrm{mL})\end{array}$ & $\begin{array}{c}\text { Boric acid spiked } \\
(\mu \mathrm{g} / \mathrm{mL})\end{array}$ & $\begin{array}{c}\text { Recovery } \\
(\% \text { mean } \pm \mathrm{SD}, n=3)\end{array}$ \\
\hline \hline & 2.0 & $92.0 \pm 0.95$ \\
3.0 & 4.0 & $96.8 \pm 1.5$ \\
& 6.0 & $106.4 \pm 0.40$ \\
7.0 & 4.0 & $100.6 \pm 0.76$ \\
& 8.0 & $97.0 \pm 0.77$ \\
$0.207 \pm 0.003^{\mathrm{a}}$ & 10.0 & $99.8 \pm 3.4$ \\
& 0.08 & $95.0 \pm 1.2$ \\
& 0.16 & $103.0 \pm 3.8$ \\
\hline
\end{tabular}

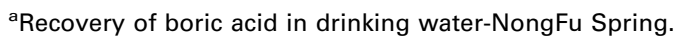


Table 2. Intra-day and inter-day precision and accuracy for the GC-MS analysis of boric acid

\begin{tabular}{|c|c|c|}
\hline & Intra-day $(n=3)$ & Inter-day $(n=5)$ \\
\hline $\begin{array}{l}\text { Nominal Conc. } \\
\qquad(\mu \mathrm{g} / \mathrm{mL})\end{array}$ & $\begin{array}{c}\text { Precision (RSD) } \\
\text { accuracy (error \%) }\end{array}$ & $\begin{array}{c}\text { Precision (RSD) } \\
\text { accuracy (error \%) }\end{array}$ \\
\hline 3.0 & $0.47-1.0$ & $4.5-4.6$ \\
\hline 7.0 & $2.8-2.8$ & $0.70-3.8$ \\
\hline
\end{tabular}

\section{Validation of GC-MS Assay}

The method linearity was investigated in the boric acid concentration range of $0.010-10.0 \mu \mathrm{g} / \mathrm{mL}$. The calibration equation is $\mathrm{Y}=79,367 \times \mathrm{X}+16,188$ and the correlation coefficient of calibration curve is 0.9988 . The sensitivity of the method was evaluated by determining the limit of detection (LOD) with a signal-to-noise $(\mathrm{S} / \mathrm{N})$ ratio of at least 3 and limit of quantification (LOQ) with a S/N ratio of at least 10 . LOD and LOQ for boric acid were found out to be $0.04 \mu \mathrm{g} / \mathrm{mL}$ and 0.08 $\mu \mathrm{g} / \mathrm{mL}$, respectively. Oshima and coworkers applied N-methyl-d-glucamine (CCTS-NMDG) to collect/adsorb boron in water samples and the LOD of boron after pretreatment with CCTS-NMDG resin and measurement by ICP-MS was $0.07 \mu \mathrm{g} / \mathrm{mL}$ and the LOQ was 0.14 $\mu \mathrm{g} / \mathrm{mL}$. The LOD of boron using ICP-AES was 0.05 $\mu \mathrm{g} / \mathrm{mL}$, while the LOQ was $0.15 \mu \mathrm{g} / \mathrm{mL}$ [20]. The standard addition recovery for sample at concentration of $3.0 \mu \mathrm{g} / \mathrm{mL}$ ranged from $92.0 \% \pm 0.95 \%$ to $106.4 \% \pm$ $0.4 \%$ and the recovery for sample at concentration of 7.0 $\mu \mathrm{g} / \mathrm{mL}$ ranged from $97.0 \% \pm 0.77 \%$ to $100.6 \% \pm 0.76 \%$ and the intra-day and inter-day precision and accuracy (error \%) were always better than 5\% (Table 1).

\section{Quantitative Analysis of Boric Acid in Drinking Water by Derivatization GC-MS}

Boric acid in bottled drinking water (Brand: NongFu Spring) was determined to be $0.207 \pm 0.003 \mathrm{mg} / \mathrm{L}$ in accordance with the value reported [21] and standard addition recovery of boric acid in NongFu Spring water ranged from $93.2 \% \pm 1.2 \%$ to $103.0 \% \pm 3.8 \%$ (Table 2).

\section{Conclusions}

In conclusion, a selective and sensitive GC-MS method in SIM mode for the determination of boric acid has been developed and validated by using triethanolamine as a derivative reagent for detecting boric acid. This method was validated and found to be satisfactorily linear, selective, and robust. Owing to no complicated sample preparation and separation steps, our derivatization GC-MS analysis method offers an effective approach for the quantitative analysis of boric acid in water samples and also has the potential application for analysis of other boron compounds with suitable sam- ple preparation methods to transform these boron compounds to boric acid.

\section{Acknowledgments}

The authors thank the National Nature Science Foundation of China (no.20805056, 20875097, 20942002, 20902104) for financial support of this work.

\section{Appendix A Supplementary Material}

Supplementary material associated with this article may be found in the online version at doi:10.1016/ j.jasms.2009.12.003.

\section{References}

1. Nielsen, F. H. Essential and Toxic Elements in Human Health and Disease, an update; Wiley-Liss: New York, 1993, p. 355.

2. Newnham, R. E. Essentiality of Boron for Healthy Bones and Joints. Environ. Health Perspect. 1994, 102, 83-85.

3. Parks J. L.; Edwards, M. Boron in the Environment. Crit. Rev. Env. Sci. Technol. 2005, 35, 81-114.

4. Bassett, J.; Matthews, P. J. A Spectrophotometric Method for the Determination of Boron in Water by Use of Ferroin. Analyst 1974, 99, 1174-1184.

5. Standard Methods for the Examination of Water and Waste Water, 13th ed.; American Public Health Authority: Washington DC, 1971; p. 69.

6. Naftel, J. A. Colorimetric Microdetermination of Boron. Ind. Eng. Chem. Anal. Ed. 1939, 11, 407-409.

7. White, C. E.; Weissler, A.; Busker, D. Fluorometric Determination of Microgram Quantities of Boron. Anal. Chem. 1947, 19, 802-805.

8. Kuwada, K.; Motomizu, S.; Tôei, K. Solvent Extraction-Spectrophotometric Determination of Boron with 2,4-dinitro-1,8-Naphthalenediol and Brilliant Green. Anal. Chem. 1978, 50, 1788-1792.

9. Krug, F. J.; Mortatti, J. Pessenda, C. R.; Zagatto, E. A. G.; Bergamin, H Flow Injection Spectrophotometric Determination of Boron in Plant Material with Azomethine-H. Anal. Chim. Acta 1981, 125, 29-35.

10. Miyazaki, A.; Bansho, K. Determination of Trace Boron in Natural Waters by Inductively Coupled Plasma Emission Spectrometry Combined with Solvent Extraction. Anal. Sci. 1986, 2, 451-455.

11. Sah, R. N.; Brown, P. H. Boron Determination-A Review of Analytical Methods. Microchem. J. 1997, 56, 285-304.

12. Sah, R. N.; Brown, P. H. Techniques for Boron Determination and Their Application to the Analysis of Plant and Soil Samples. Plant Soil 1997, 193, 15-33.

13. Sun, D. H.; Waters, J. K.; Mawhinney, T. P. Microwave Digestion and Ultrasonic Nebulization for Determination of Boron in Animal Tissues by Inductively Coupled Plasma Atomic Emission Spectrometry with Internal Standardization and Addition of Mannitol. J. Anal. At. Spectrom. 1997, 12, 675-679.

14. Xu, L.; Rao, Z. Determination of Boron in Soils by Sequential Scanning ICP-AES Using Side Line Indexing Method. Fresenius Z Anal. Chem. 1986, 325, 534-538.

15. Smith, F. G.; Wiederin, D. R.; Houk, R. S.; Egan, C. B.; Serfass, R. E. Measurement of Boron Concentration and Isotope Ratios in Biological Samples by Inductively Coupled Plasma Mass Spectrometry with Direct Injection Nebulization. Anal. Chim. Acta 1991, 248, 229-234.

16. Brown, H. C.; Fletcher, E. A. Compounds with Boron at the BridgeheadA Study of the Steric Consequences of Planar Boron. J. Am. Chem. Soc. 1951, 73, 2808-2813.

17. Korlyukov, A. A.; Lyssenko, K. A.; Antipin, M. Y.; Kirin, V. N.; Chernyshev, E. A.; Knyazev, S. P. Experimental and Theoretical Study of the Transannular Intramolecular Interaction and Cage Effect in the Artane Framework of Boratrane and 1-Methylsilatrane. Inorg. Chem. 2002, 41, 5043-5051.

18. Mann, S.; Geilenberg, D.; Broekaert, J. A. C.; Jansen, M. Digestion Methods for Advanced Ceramic Materials and Subsequent Determination of Silicon and Boron by Inductively Coupled Plasma Atomic Emission Spectrometry. J. Anal. At. Spectrom. 1997, 12, 975-979.

19. Sun, D. H.; Waters, J. K.; Mawhinney, T. P. Microwave Digestion and Ultrasonic Nebulization for Determination of Boron in Animal Tissues by Inductively Coupled Plasma Atomic Emission Spectrometry with Internal Standardization and Addition of Mannitol. J. Anal. At. Spectrom. $1997,12,675-679$. 
20. Sabarudin, A.; Oshita, K.; Oshima, M.; Motomizu, S. Synthesis of CrossLinked Chitosan Possessing N-methyl-d-glucamine Moiety (CCTSNMDG) for Adsorption/Concentration of Boron in Water Samples and its Accurate Measurement by ICP-MS and ICP-AES. Talanta 2005, 66, 136-144.
21. Zhang, W. D.; Zhao, N. P. Determination of Boric Acid in Natural Mineral Water for Dinking by 1-(2-Hydroxy-3-MethoxybenzylidenceAmino)-8-Hydroxynaphalene-3-6-Disulfonic Acid Spectrophotometry. J. Environ. Health 2001, 18, 172-173. 